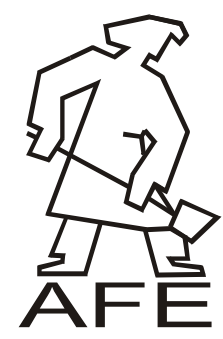

\title{
The Effect of Major Alloying Elements on the Size of Secondary Dendrite Arm Spacing in the As-Cast Al-Si-Cu Alloys
}

\author{
M. B. Djurdjevič ${ }^{a} *$, M. A. Grzinčič ${ }^{\mathbf{b}}$ \\ ${ }^{a}$ Product Development Center, Nemak Linz GmbH, Zeppelinstrasse 24, 4030 Linz, Austria \\ ${ }^{\mathrm{b}}$ Process Engineering Department, Nemak Slovakia s.r.o., Ladomerská Vieska 394, 96501 Žiar nad Hronom, Slovakia \\ *Corresponding author. E-mail address: mile.djurdjevic@nemak.com
}

Received 01.02.2012; accepted in revised form 20.03.2012

\begin{abstract}
A comprehensive understanding of melt quality is of paramount importance for the control and prediction of actual casting characteristics. Among many phenomenon that occur during the solidification of castings, there are four that control structure and consequently mechanical properties: chemical composition, liquid metal treatment, cooling rate and temperature gradient. The cooling rate and alloy composition are most important among them. This paper investigates the effect of the major alloying elements (silicon and copper) of Al$\mathrm{Si}-\mathrm{Cu}$ alloys on the size of secondary dendrite arm spacing. It has been shown that both alloying elements have reasonable influence on the refinement of this solidification parameter.
\end{abstract}

Keywords: Secondary dendrite arm spacing; AlSiCu alloy; Aluminium casting; Solidification

\section{Introduction}

Casting is the process of melting metals and pouring them into a mold in order to produce the required solid shape. It is the simplest and most economical process, and sometimes the only technically feasible method of obtaining a required solid shape. The process is applicable to a variety of materials such as metals, ceramics, plastics and glass. Among metals, aluminium alloys have been in widespread use in the automotive industry due to their good casting characteristics and mechanical properties. This is mainly due to the outstanding effect of silicon and copper in the improvement of casting characteristics, combined with other physical properties, such as mechanical properties and corrosion resistance. Silicon is one of the most significant alloying elements incorporated in aluminium alloys. Its addition is used to improve castability, fluidity, reduce shrinkage and to render superior mechanical properties. The presence of copper improves tensile strength at the expense of a reduction in ductility and corrosion resistance.

In designing cast automotive parts, it is important, besides chemical composition, to have an intimate knowledge of how the alloy solidifies at different cross sections of the cast part and how this influences mechanical properties. This knowledge enables the designer to ensure that the casting will achieve the desired properties for its intended application. Of the many phenomenon that occur during the solidification of castings, there are four that control structure and consequently mechanical properties: chemical composition, liquid metal treatment, cooling rate and temperature gradient. Among them, cooling rate plays the most significant role. The effect of cooling rate on the structural features of aluminium alloys such as grain size, secondary dendrite arm spacing (SDAS), eutectic silicon structure and the 
morphology of iron and manganese phases has been investigated by many authors [1-10]. The general consensus from the previous work is that increasing the cooling rate refines the grain size, modifies silicon particles, and decreases SDAS.

Figure 1 shows that the solidification of cast Al-Si-Cu alloys starts at liquidus temperature with the precipitation of the primary alpha phase from the liquid. The microstructure of a sample from an $\mathrm{AlSiCu}$ alloy shows a bulky area of an $\alpha$-Al matrix, large needles form of $\mathrm{Al}-\mathrm{Si}$ eutectic (dark), and $\mathrm{AlCu} 2$ eutectic precipitated particles (pink). The lines with arrows indicate the approximated temperatures at which theses phases start to precipitate. The total solidification time of a generic $\mathrm{AlSiCu}$ alloy is also depicted.

A primary $\alpha$-aluminium dendrite network forms between 580 $-610^{\circ} \mathrm{C}$. The exact temperature depends mainly on the amount of silicon and copper in the alloy. The primary phase grows as solid crystals having a dendritic shape. This leads to an increase in the concentration of silicon and copper in the remaining liquid. The first temperature plateau on the cooling curve (aluminium silicon eutectic temperature) can be recognized between 570 $555^{\circ} \mathrm{C}$. Reaching the aluminium-silicon eutectic temperature, the solidification proceeds at a constant temperature with the formation of the eutectic solid phase in the space left between the dendrite arms. In the copper enriched phase, represented by the second plateau, the dendritic network of $\alpha$-Al crystals start to precipitate (between $525-507^{\circ} \mathrm{C}$ ) from the last portion of the melt close to the solidus temperature.

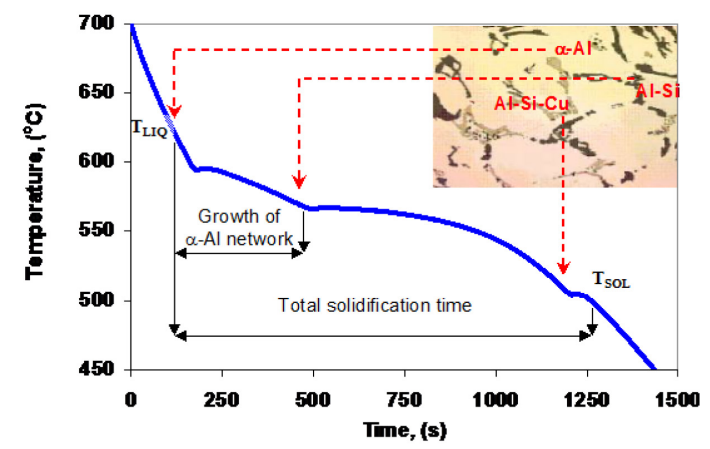

Fig. 1. The cooling curve of AlSiCu alloy with schematically designated areas of typically precipitated phases

As can be seen in Figure 1, the solidification of any alloy starts at the liquidus temperature with undercooling related to the formation of many small crystal nuclei in the melt. Further cooling of the melt is followed by the precipitation of the primary dendritic network of $\alpha$-Al crystals. A dendrite is a characteristic tree-like structure of crystal growing as molten metal freezes. Dendrites normally grow from a single nucleus both forwards (primary) and sideways (secondary), which may be only a few microns in diameter. At the beginning, the primary dendrite arm growth occurs until they reach each other at a certain temperature (dendrite coherency temperature) and fraction solid (dendrite coherency fraction). The further development of the $\alpha$-aluminium dendritic structure is characterized by the growth of secondary or even tertiary branches, which grow in the preferred crystallographic direction.
The most important practical aspect of the dendritic structure is SDAS, representing the distance between secondary dendrites in the solidifying structure of cast metals and alloys. This quantity is significant because it has been shown that many mechanical properties can be related to it $[1-4,8,11,14,15]$, with the best properties always associated with the smallest SDAS. In many ways, SDAS is just a measure of the overall fineness of the cast microstructure. A small value of SDAS implies that the structure is fine, with all of the associated benefits including smaller grains, finer intermetallics, better microhomogeneity and less, as well as better distributed porosity. All of these desirable features of the cast structure are responsible for the good mechanical properties associated with small SDAS. As can be seen in Figure 2, there is an inverse relationship between the cooling rate and SDAS (e.g. the higher the cooling rate, the lower SDAS) [1]. The choice of six alloys gives a good indication how various contents of alloying elements (especially silicon and copper) effect the size of DAS.

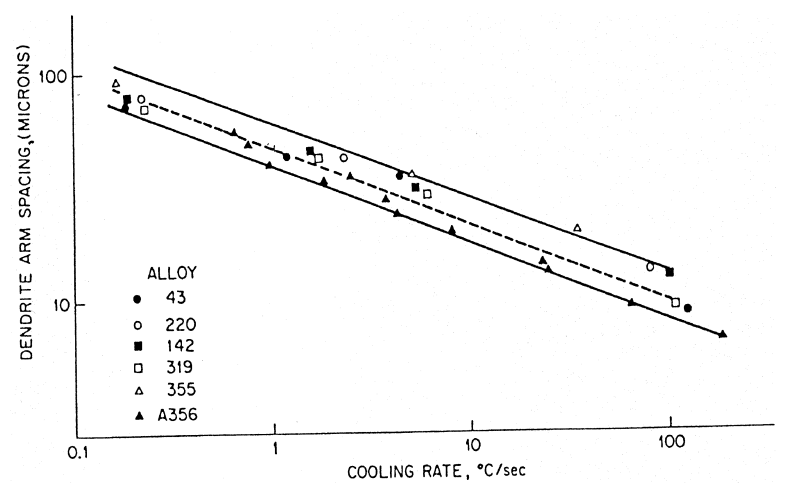

Fig. 2. The effect of average cooling rate on the size of dendrite arm spacing for six aluminium alloys [1]. The data cover a range of cooling rates of three orders of magnitude

Spear et.al. [1] in their paper, discussed the methods of measuring dendrite microstructure and the effect of solidification rate and alloy composition on cell size. According to them, there are at least three different measurements which may be used to describe dendrite refinement. These measurements are: dendrite arm spacing, dendrite cell size and dendrite cell interval. Dendrite arm spacing is the distance between the developed secondary arms; dendrite cell interval is the distance between centre lines of adjacent dendrite cells; and dendrite cell size is the width of the individual cells. An excellent discussion about the best method of measuring dendrite size is contained in reference 1 . The relationship between cooling rate and dendrite size was investigated for six aluminium alloys at various rates. Figure 2 shows the results of their investigation. As can be seen, the size of the dendrites is strongly affected by the cooling rate. However, the chemical composition of the alloys has also some effect on this structural characteristic. This effect is not easily recognized due to the leading effect of the cooling rate. Unfortunately, the effect of the chemistry on SDAS has not been extensively investigated in the literature. Recently, Zhang et.al. [4] studied the influence of process parameters such as chemical composition, cooling rate, mold temperature and pouring temperature on the size of SDAS of cast aluminium cylinder heads. The influence of chemical composition has been analysed using three aluminium 
alloys AlSi7Mg0.3, AlSi9Cu1Mg0.3 and AlSi7Cu3Mg0.3. They found that various contents of silicon and copper have a significant effect on the size of SDAS even at a high cooling rate. However, both papers did not cover the full range of silicon and copper contents. Such studies could be interesting for producers of as-cast automotive parts. Therefore, in the present work the aim has been to assess the effect of major alloying elements such as silicon and copper on the size of SDAS of the Al-Si-Cu series of alloys produced under similar conditions and studied by identical techniques. In order to achieve this the content of the silicon was varied from 1 to $10 \mathrm{wt} . \%$ while the content of copper was in the range from 0 to $5 \mathrm{wt}, \%$.

\section{Experimental Procedure}

\subsection{Materials}

Eleven synthetic Al-Si compositions were produced at the Nemak casting research and development department. The experiments were performed using an Al-Sil1 alloy with traces of $\mathrm{Cu}, \mathrm{Mg}$ and other elements (for details see alloy 1 in Table 1), that has been diluted by adding a certain amount of pure aluminium in order to reach the desired content of silicon. The chemical compositions of the resulting alloys with different contents of silicon (only major alloying elements are presented, all contents in wt.\%), as determined using (OES) are presented in Table 1 .

Table 1.

\begin{tabular}{ccccccc}
\hline Alloy & Si & $\mathrm{Fe}$ & $\mathrm{Cu}$ & $\mathrm{Mn}$ & $\mathrm{Mg}$ & $\mathrm{Zn}$ \\
\hline 1 & $\mathbf{1 0 . 9 9}$ & 0.09 & 0.002 & 0.04 & 0.32 & 0.007 \\
\hline 2 & $\mathbf{9 . 7 1}$ & 0.08 & 0.001 & 0.03 & 0.24 & 0.006 \\
\hline 3 & $\mathbf{8 . 5 9}$ & 0.10 & 0.001 & 0.03 & 0.24 & 0.006 \\
\hline 4 & $\mathbf{7 . 5 7}$ & 0.10 & 0.002 & 0.03 & 0.22 & 0.006 \\
\hline 5 & $\mathbf{6 . 9 7}$ & 0.10 & 0.002 & 0.03 & 0.22 & 0.007 \\
\hline 6 & $\mathbf{6 . 0 5}$ & 0.11 & 0.002 & 0.02 & 0.21 & 0.007 \\
\hline 7 & $\mathbf{4 . 7 0}$ & 0.11 & 0.002 & 0.02 & 0.21 & 0.007 \\
\hline 8 & $\mathbf{3 . 7 2}$ & 0.12 & 0.002 & 0.02 & 0.19 & 0.009 \\
\hline 9 & $\mathbf{2 . 7 5}$ & 0.12 & 0.002 & 0.02 & 0.18 & 0.009 \\
\hline 10 & $\mathbf{2 . 0 6}$ & 0.13 & 0.002 & 0.02 & 0.17 & 0.008 \\
\hline 11 & $\mathbf{1 . 3 0}$ & 0.13 & 0.002 & 0.02 & 0.17 & 0.009 \\
\hline
\end{tabular}

In order to analyse the effect of various contents of copper on the size of SDAS, nine synthetic Al-Si-Cu compositions were produced by melting a charge of Al- 6 wt. $\%$ Si- 0.002 wt. $\%$ Cu base alloy (alloy 6 from Table 1 has been used as the starting alloy). To reach the targeted content of copper, various amounts of pure copper and Al-Si master alloy were added to the melt. Table 2 shows the chemical composition of the resulting alloys.

Table 2.

\begin{tabular}{ccccccc}
\hline Alloy & $\mathrm{Si}$ & $\mathrm{Fe}$ & $\mathbf{C u}$ & $\mathrm{Mn}$ & $\mathrm{Mg}$ & $\mathrm{Zn}$ \\
\hline 1 & 6.02 & 0.08 & $\mathbf{0 . 3 7}$ & 0.002 & 0.21 & 0.005 \\
\hline 2 & 6.09 & 0.08 & $\mathbf{0 . 7 6}$ & 0.002 & 0.30 & 0.005 \\
\hline 3 & 6.19 & 0.07 & $\mathbf{1 . 4 2}$ & 0.002 & 0.27 & 0.005 \\
\hline 4 & 6.25 & 0.08 & $\mathbf{1 . 7 6}$ & 0.002 & 0.28 & 0.004 \\
\hline 5 & 6.15 & 0.07 & $\mathbf{2 . 1 3}$ & 0.002 & 0.25 & 0.005 \\
\hline
\end{tabular}

\begin{tabular}{lllllll}
\hline 6 & 6.07 & 0.07 & $\mathbf{2 . 2 3}$ & 0.002 & 0.26 & 0.005 \\
\hline 7 & 6.10 & 0.07 & $\mathbf{2 . 6 0}$ & 0.002 & 0.26 & 0.005 \\
\hline 8 & 6.21 & 0.07 & $\mathbf{3 . 2 0}$ & 0.002 & 0.27 & 0.005 \\
\hline 9 & 6.17 & 0.08 & $\mathbf{4 . 7 1}$ & 0.002 & 0.25 & 0.004 \\
\hline
\end{tabular}

\subsection{Melting Procedure}

Previously prepared samples for each targeted alloys is firstly charged in ceramic cups, loaded in an electric resistance furnace and melted. During all experiments the melt temperature was kept constant at $700^{\circ} \mathrm{C} \pm 5^{\circ} \mathrm{C}$. After melting down, all samples with masses of approximately $80 \mathrm{~g} \pm 2 \mathrm{~g}$ where left to solidify under the same conditions. A thermoelement was inserted into the test sample (alloy 1 from Table 1) in order to determine the cooling rate. The temperature range between liquidus and solidus temperatures divided by the total solidification time (see Figure 1) has been used to calculate the rate of solidification. The cooling rate for all samples was $0.15^{\circ} \mathrm{C} / \mathrm{sec}$.

\subsection{Metallography}

Solidified cylindrical samples are sectioned vertically. One half of the sample has been used for chemical analysis while other half has been used for quantitative measurements of SDAS. Metallographic samples were prepared by standard grinding and polishing procedures. A Zeiss Axiotech light optical microscope was used in this work for SDAS measurements. Figure 3 depicts the difference between DAS and SDAS.

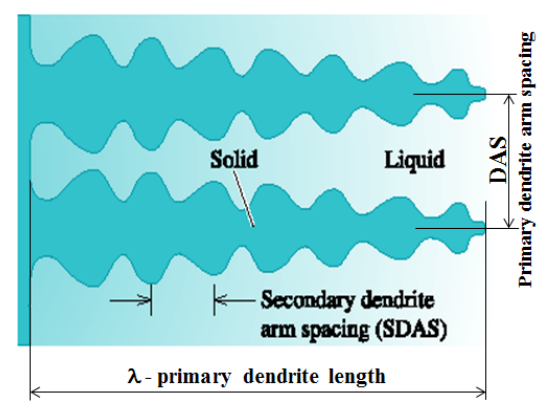

Fig. 3. Schematic representation of dendrites showing the difference between primary and secondary dendrite arm spacing

SDAS is a measure of the length scale between two adjacent SDAS, and it is usually an order of magnitude smaller than the primary arm spacing. In this work, the line intercept method was utilized to measure SDAS. The applied magnification was 25 times. The size of SDAS was obtained as a average value of at least 10 measurements.

\section{Results and Discussions}

$\mathrm{AlSiCu}$ alloys constitute one of the commercially important classes of Al alloys. These alloys are extensively used in the production of intricate automotive parts such as engine block and cylinder heads. This usage often requires excellent mechanical 
properties of these alloys. In order to achieve this requirement, the structure of the cast part has to be closely controlled by obtaining diverse cross sections. It is well known that various cooling rates during solidification can lead to variation in the amount and shape of various morphological characteristics of as-cast structures, which in turn can lead to different mechanical properties. A wellknown effect of varying cooling rates on the size of SDAS is effusively exploited in the literature [1- 4, 11-14, 17-19]. In addition the effect of alloying elements on the size of SDAS by aluminium-silicon alloys was not so extensively investigated. Only a few researchers [1, 4] have examined the effect of variation in the alloy composition on the size of SDAS. Generally, it has been found that various contents of silicon and copper have some effect on the size of SDAS, although the effect is usually small comparing with that obtained by varying the cooling rate. The present work studies the effect of major alloying elements, silicon and copper, on the size of SDAS in the Al-Si-Cu alloys.

\subsection{The influence of silicon and copper on the size of SDAS}

The dendritic structure of aluminium alloys is a key microstructural feature, characterized mostly by the primary and secondary arm spacing as it has been schematically shown in Figure 3. For the as-cast or heat treated conditions, the fineness of these individual properties is recognized to yield superior mechanical properties over coarser ones $[1-4,8,15,16]$. The influence of various contents of the silicon and copper on the size of SDAS is presented in Figures 4 and 5. Each point on Figures 4 and 5 corresponds to the average value of SDAS based on the ten measurements. Vertical bars represent the standard deviations for each series of measurements. Higher silicon and copper contents reduced the size of SDAS. When the content of silicon increased above 8 wt.\%, this effect is insignificant; any increase above 3 wt.\% of copper refined the dendrite but at a much lower rate. Dependence between SDAS and silicon or copper content could be expressed by second order polynomial equations with a high correlation coefficient.

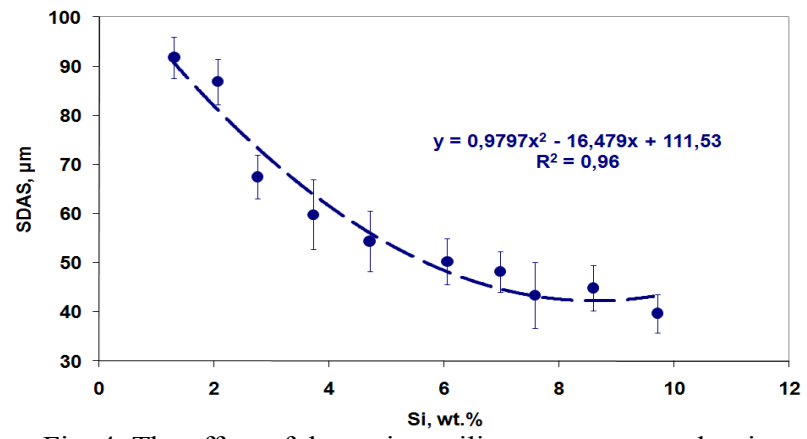

Fig. 4. The effect of the various silicon contents on the size of

SDAS. There is an appreciable refining effect as the content of silicon varied between 1 and 8 weight percent.

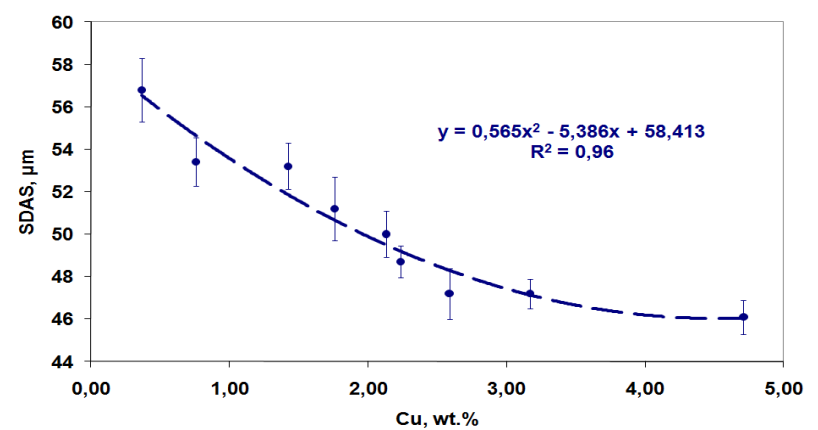

Fig. 5. The effect of the various copper contents on the size of SSDAS. The increases in the copper content from 0 to 3 weight percent have a considerable affect on the size of SDAS.

Microstructural changes that occur with the increasing silicon content are shown in Figures 6 (a to e). These micrographs depict the development of a smaller SDAS as silicon content increases. Structure analysis presented in Figures 6 and 7 show that the addition of silicon and/or copper decreases the size of SDAS. Measurements done by image analysis confirmed that the average size of SDAS decreased from $91.8 \mu \mathrm{m}$ to $39.7 \mu \mathrm{m}$ according to addition of silicon from 1 to $10 \mathrm{wt} \%$ respectively. The effect is more significant until silicon reaches the content of 8 wt.\%. A further increase in the content of silicon has almost no effect on the size of this microconstituent.

A similar, though considerably smaller effect, can be recognized by the addition of copper in the AlSiCu melt. The data presented in Figure 5 shows that the size of SDAS slightly decreases from $56.8 \mu \mathrm{m}$ to $46.1 \mu \mathrm{m}$ when the content of copper in the $\mathrm{AlSiCu}$ melt increases to approximately $4.7 \mathrm{wt} . \%$.

These results are not unexpected. It is well known from the literature $[1,19]$, that the size of the dendrites is, besides the cooling rate of solidification, dependent on the level of alloying elements present in the melt. During the primary solidification of the aluminium alloys, the alloying elements are not evenly distributed between the solid and liquid phases. An excess amount of solute displaces away from the solidification interface into the melt resulting in the increase in the volume of solute placed between already formed dendrite arms. This supersaturation (or related constitutional undercooling) represents the driving force for the growth of dendrites. The space between $\alpha$-aluminium dendrite arms must increase to accommodate an increasing amount of solute elements. Next, a higher concentration of alloying elements will cause the precipitation of finer dendrites and vice versa, dendrites at low concentrations are more spherical in appearance as illustrated in Figures 6a, 6e, 7a and 7e.

It is also expected that the elements with a higher solubility in the aluminium melt are less effective in reducing the size of SDAS. Therefore, the effect of the same content of copper is slightly smaller than that of the same content of silicon.

Comparing the results from figure 2 with the results presented in Figures 4 and 5 , it is evident that the cooling rate has a more significant effect on the size of SDAS compared to the chemical composition of the alloy.

So, by designing a cast product, the effect of the cooling rate on SDAS has to be considered in advance. At the same time the effect of the chemical composition cannot be neglected. Especially in the case when the chemical composition of elements 
defined by a customer are given in a broad range. Picking up either the lower $(6.0 \mathrm{wt} . \%)$ or upper $(8.0 \mathrm{wt} . \%)$ content of silicon from the AlSi7Mg (356 alloy according to American nomenclature) alloy specification, distinctly change the size of SDAS in the solidified as-cast structure for approximately $7 \mu \mathrm{m}$. Therefore, the effect of chemistry on the size of SDAS has to be understood and properly used in order to obtain the requested quality of the cast product. This effect is getting more important as we are closer to the riser side of our cast product. Consequently, the effect of the chemical composition should be used for fine tuning to reach the desired size of SDAS.
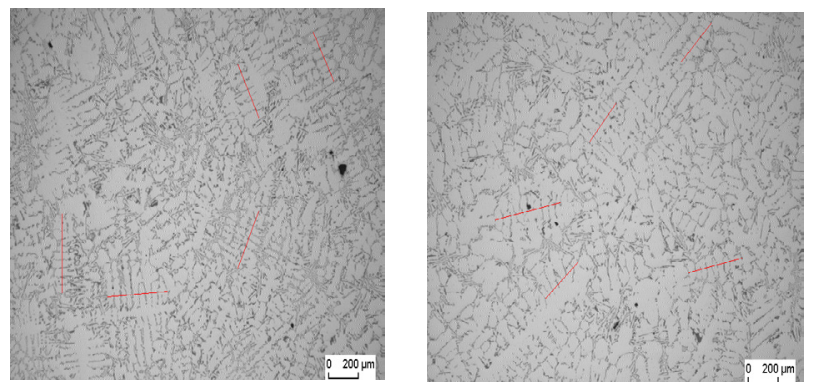

a) Al -10 wt.\% Si alloy

b) Al - 8 wt.\% Si alloy
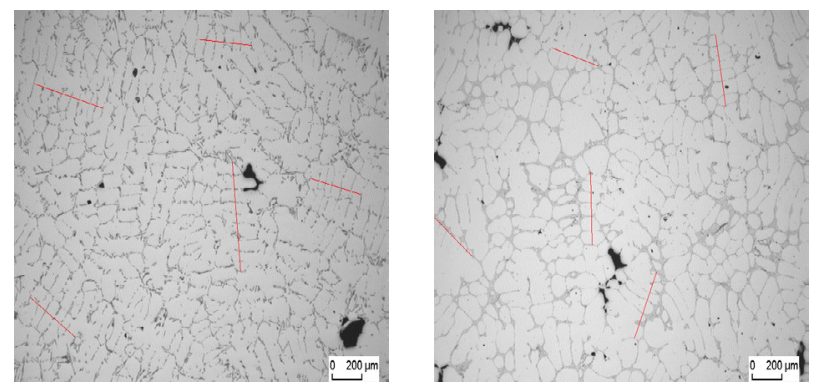

c) Al - 6 wt.\% Si alloy

d) Al - 4 wt.\% Si alloy

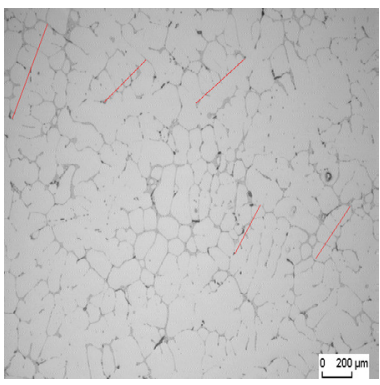

e) Al - 2 wt. \% Si alloy

Fig. 6. Light optical micrographs of aluminum-silicon alloys as a function of various content of silicon

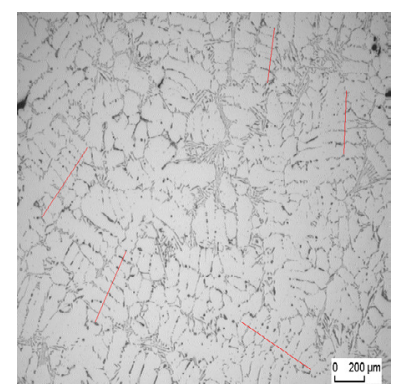

a) $\mathrm{Al}$ - Si 6 - Cu 0.76 alloy

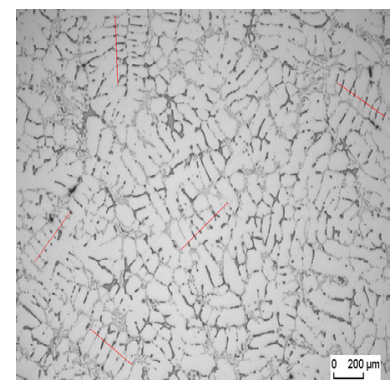

c) $\mathrm{Al}$ - Si 6 - Cu 2.23 alloy

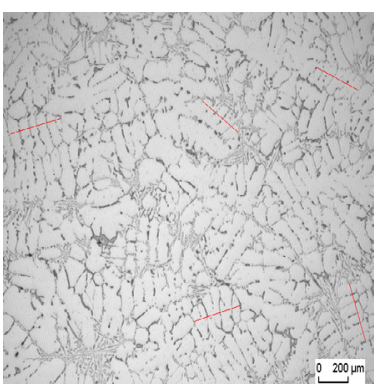

b) $\mathrm{Al}$ - Si 6 - Cu 1.76 alloy

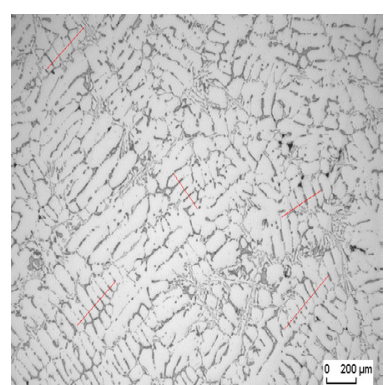

d) Al - Si 6 - Cu 3.20 alloy

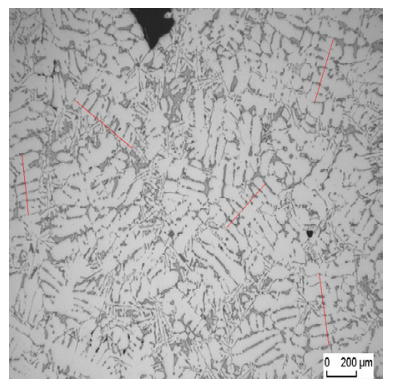

e) $\mathrm{Al}$ - Si 6 - Cu 4.71 alloy

Fig. 7. Optical micrographs showing the effect of various contents of copper (wt.\%) in Al-Si-Cu alloys on the size of SDAS

\section{Conclusions}

Experiments were carried out to observe the effect of silicon additions between 1.3 and 9.7 wt.\% and copper additions between 0.37 and 4.7 wt. $\%$ on the size of secondary dendrite arm spacing (SDAS) in Al-Si-Cu alloys. It was found that the addition of silicon and copper slightly reduced the size of SDAS comparing to the effect of the cooling rate but still not so insignificant that they influence can be ignore. This decrease in the size of SDAS seems to correlate well with the formation of a large volume of solute during solidification of the aluminium alloys with a high content of silicon and copper. The obtained results are in agreement with data contained in the available literature. 


\section{References}

[1] Spear, R.E. \& Gardner, G.R. (1963). Dendrite cell size. AFS Transactions. 71, 209-215.

[2] Rhadhakrishna, K, Seshan, S., \& Seshadri, M.R. (1980). Dendrite arm spacing in aluminium alloy castings, $A F S$ Transactions 88, 695-702.

[3] Flemings, M. Kattamis, T.Z. \& Bardes, B.P. (1991). Dendrite arm spacing in aluminium alloys. AFS Transactions 99, 501-506.

[4] Zang, B., Garro, M., \& Tagliano, C. (2003). Dendrite arm spacing in aluminium alloy cylinder heads produced by gravity semi-permanent mold. Metallurgical Science and Technology 21, 3-9.

[5] Davis J.R. (Eds.), (1994). ASM Specialty Handbook, Aluminium and Aluminium Alloys; ASM International, The Materials Information Society, 10-60.

[6] ASM Handbook Volume 3: Alloy Phase Diagrams (1992). The Materials Information Society, 1-40.

[7] Ciach, R. \& Podosek, M. (1997). Solidification of Aluminum Alloys, In Proceedings of the NATO Advanced Studies, Institute on Advanced Light Alloys and Composites, Zakopane, Poland, September 5-15, 201-206.

[8] Backerud, L. (1991). Solidification Characteristics of Aluminium Alloys. In AFS Skanaluminium Vol. 2 (1-75).

[9] Bennon, W.D. Incropera, F.P. (1987). A Continuum Model for Momentum, Heat and Species Transport in Binary SolidLiquid Phase Change Systems. Int. J. Heat Mass Transfer 30, 2161-2187.

[10] Caceres, C.H. Djurdjevic, M.B. Stockwell, T.J. \& Sokolowski, J.H. (1999). The Effect of Cu Content on the Level of Microporosity in Al-Si-Cu-Mg Casting Alloys. Scripta Materialia 40, 631-637.

[11] Gruzleski, J.E. \& Closset, B.M. (1990). The treatment of liquid aluminium-silicon alloys. American Foundryman's Society, Inc. Des Plaines, Illinois, USA, 1-35.
[12] Tenekedjiev, N., Mulazimoglu, H., Closset, B. \& Gruzleski, J. (1995). Microstructures and Thermal Analysis of Strontium-Treated Aluminium-Silicon Alloys, American Foundryman's Society, Inc. Des Plaines, Illinois, USA, 4041.

[13] Matuja, H., Giessen, B.C. \& Grant, N.J. (1968). The effect of cooling rate on the dendrite spacing in splat-cooled aluminium alloys. The Journals of the Institute of Metals. (9), 30-32.

[14] Ananthanarayanan, L. \& Gruzleski, J.E. (1992). Thermal Analysis Studies on the Effect of Cooling Rate on the Microstructure of the 319 Aluminium Alloy. AFS Transactions. 141, 383-391.

[15] Gowri, S. Comparison of thermal analysis parameters of 356 and 359 alloys. AFS Transactions. 94 (29), 503-508.

[16] Kang, H.G., Miyahara, H. \& Ogi, K. (1995). Influence of cooling rate and additions of $\mathrm{Sr}$ and $\mathrm{Ti}-\mathrm{B}$ on solidification structures of AC4B type alloy. In Proceedings of the $3^{\text {rd }}$ Asian Foundry Congress, edited by Lee Z. H., Hong C. P., and Kim M.H., November 8-10 (108-115). Kyongju Korea: The Korean Foundrymen's Society.

[17] Chen, Y.F., Jong, S.H. \& Hwang, W.S. (1995). The effect of cooling rate on the latent heat released mode for near pure aluminium and aluminium silicon alloy. In Cross, M. \& Campbell, H. J. (Eds.), Modelling of Casting, Welding and Advanced Solidification Processes, VII Edition (483-490). The Minerals, Metals and Materials Society.

[18] Figueredo, A.M., Sumartha, Y. \& Flemings, M.C. (1998). Measurement and calculation of solid fraction in quenched semi-solid melts of rheocast aluminium alloy A357. In Welch, B. (Ed.), Light Metals (1103-1106). The Minerals, Metals and Materials Society.

[19] Gruzleski, J. E. (2000). Microstructure development during metal casting, $A F S$ (99-116). Des Plaines Illinois.. 